\title{
Application of 2-octyl-cyanoacrylate for corneal perforation and glaucoma filtering bleb leak
}

This article was published in the following Dove Press journal:

Clinical Ophthalmology

27 March 2013

Number of times this article has been viewed

\section{Motonori Okabe' \\ Kiyotaka Kitagawa ${ }^{2}$ \\ Toshiko Yoshida' \\ Chika Koike' \\ Takeshi Katsumoto ${ }^{2}$ \\ Etsuko Fujihara ${ }^{2}$ \\ Toshio Nikaido' \\ 'Department of Regenerative Medicine, University of Toyama, \\ Graduate School of Medicine and Pharmaceutical Sciences, Toyama, \\ ${ }^{2}$ Division of Ophthalmology, Matsue \\ Red Cross Hospital, Japanese Red \\ Cross Society, Shimane, Japan}

Correspondence: Kiyotaka Kitagawa Division of Ophthalmology, Matsue Red Cross Hospital, 200 Horomachi, Matsue, Shimane 690-8506, Japan

$\mathrm{Tel}+8 \mathrm{I} 852242$ III

Fax +81852319783

Email kiyotaka_kitagawa@matsue.jrc.or.jp
Background: This paper reports on the efficacy of a tissue adhesive, 2-octyl-cyanoacrylate, in the treatment of corneal perforation and glaucoma filtering bleb leak.

Methods: Two eyes from two patients with corneal perforation or laceration and two eyes from two patients with bleb leak were included. The patients underwent application of 2-octyl-cyanoacrylate onto the perforated or leaking site, and a hydrogel contact lens was applied as a bandage. We also evaluated the in vitro cell toxicity of 2-octyl-cyanoacrylate in HeLa cells.

Results: The two cases of corneal perforation were repaired within 22 days with one application of the tissue adhesive. The two cases of bleb leak were repaired with 2-4 applications of the tissue adhesive over 134 (range 17-134) days). There were no recurrences or adverse effects during a mean follow-up period of 12.7 months. In vitro testing revealed that 2-octylcyanoacrylate was markedly toxic to HeLa cells.

Conclusion: Four patients with corneal perforation or bleb leak were successfully managed using 2-octyl-cyanoacrylate tissue adhesive. This simple and easy surgical technique may become an alternative therapeutic option for corneal perforation or bleb leak, although several applications of this tissue adhesive may be required. Although 2-octyl-cyanoacrylate was toxic to HeLa cells, no adverse clinical effects were noted using this adhesive.

Keywords: corneal perforation, bleb leak, tissue adhesive, 2-octyl-cyanoacrylate

\section{Introduction}

Corneal perforation and glaucoma filtering bleb leak are ocular emergencies which are frequently encountered in ophthalmic practice, and can result in vision-threatening ocular complications, such as bacterial endophthalmitis. We recently reported on the efficacy of a hyperdry human amniotic membrane (HD-AM) patch in combination with 2-octyl-cyanoacrylate tissue adhesive in the treatment of corneal perforation and bleb leak. ${ }^{1-3}$ HD-AM is processed by consecutive far-infrared rays and microwaves, then sterilized by gamma-ray irradiation, and can be stored at room temperature. This Hyper Dry method is a tissue-sparing drying method. Topical application of several tissue adhesives, including cyanoacrylate derivatives or fibrin glue, has been reported to be effective in the management of corneal perforation, cataract surgery, and glaucoma bleb leak..$^{4-9}$ In the present study, we evaluated the efficacy of the tissue adhesive (2-octyl-cyanoacrylate) without HD-AM patching for corneal perforation and bleb leak, and the toxicity of 2-octyl-cyanoacrylate in HeLa cells in vitro.

\section{Materials and methods}

Two patients with corneal perforation or laceration (two eyes) and two patients with bleb leak (two eyes) were examined. The mean patient age was 42.5 (range 18-82) years. 
The male to female ratio was 1:3. All surgical procedures were performed at the Matsue Red Cross Hospital between July 2010 and November 2010 after the patients had been informed of the risks and the alternative treatments available. Written informed consent for treatment was obtained from each patient before the surgical procedure. This study was approved by the ethics committee at Matsue Red Cross Hospital.

\section{Surgical procedure}

All four patients underwent application of the tissue adhesive in the minor procedure room under topical anesthesia with $2 \%$ lidocaine. A drop of 2-octyl-cyanoacrylate was applied to the top of a glass cylinder mounted with $0.3 \%$ ofloxacin ophthalmic ointment. With a lid speculum keeping the lid open and the eye looking downward, the precise perforated or leaking site was identified using an operating microscope. After the perforated site was dried with a cellulose sponge, the tissue adhesive-applied glass cylinder was pressed promptly onto the lesion, which was then allowed to dry in air for one minute, followed by topical instillation of $0.5 \%$ levofloxacin. A hydrogel contact lens was installed to minimize discomfort and prevent dislocation of the glue patch. This contact lens was not removed until the glue applied had dislodged from the wound.

\section{In vitro testing of cytotoxicity}

A suspension of HeLa cells was centrifuged at $150 \mathrm{~g}$ for 5 minutes and resuspended at a density of $10 \times 10^{4} \mathrm{cells} / \mathrm{cm}^{2}$ in high-glucose Dulbecco's modified Eagle medium (SigmaAldrich, Co., St Louis, MO, USA) supplemented with 10\% heat-inactivated fetal bovine serum (PAA Laboratories, Pasching, Austria) and 1\% antibiotic-antifungal solution (09366-44, Nacalai Tesque, Kyoto, Japan). The HeLa cells were seeded onto a HD-AM and onto a freeze-dried human amniotic membrane (FD-AM) anchored by collagen gel. In the same way, HeLa cells were seeded on collagen gel and 2-octylcyanoacrylate in six-well culture dishes (657160, Greiner Bio-One, Tokyo, Japan). The cells were seeded at $3 \mathrm{~mL} /$ well and cultured in a humidified atmosphere of $5 \% \mathrm{CO}_{2}$ in air at $37^{\circ} \mathrm{C}$ for 48 hours. The condition of the cells was observed by inverted microscopy (Ecrips 200, Nikon, Tokyo, Japan).

\section{Results}

\section{In vitro testing of cytotoxicity}

HeLa cells grew and covered the HD-AM, FD-AM, and collagen gel (Figure 1A, B, and D). However, HeLa cells could not survive near 2-octyl-cyanoacrylate (Figure 1C).

\section{Clinical outcome}

The clinical data and outcomes for the four patients are summarized in Table 1. The mean follow-up period after application of the glue was 12.7 (range 3-18) months. The mean number of reapplications of 2-octyl-cyanoacrylate was two per eye in four patients (range 1-4 times). There was no need for reapplication of the adhesive in the eyes with corneal perforation. The healing times for the eyes with corneal perforation were 22 days and 19 days in patient 1 and 2 , respectively. Corneal re-epithelization was observed over the repaired area. Any corneal damage potentially induced by the tissue adhesive was not detected during the postoperative follow-up period.

Reapplication of the adhesive was required for the management of glaucoma filtering bleb leak. In patients 3 and 4, the number of reapplications of adhesive was four and two times, respectively. The healing times for the conjunctival bleb leak site were 134 days and 17 days in patients 3 and 4, respectively. No adverse conjunctival effects induced by the adhesive were detected during the postoperative follow-up period.

\section{Patient 2}

In October 2010, an 82-year-old woman was referred to our clinic because of a corneal perforation of the left eye. The patient had undergone corneal tattooing due to congenital syphilitic corneal opacity at another clinic about 40 years earlier, and visual acuity in her left eye had been light perception since then. On examination, corneal perforation with a descemetocele
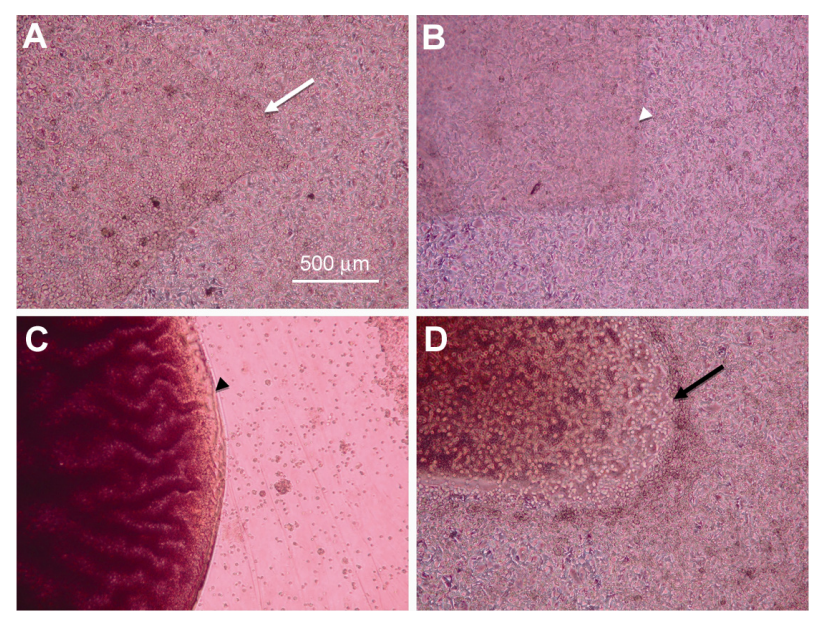

Figure I Micrograph of cultured HeLa cells under the different conditions. (A) HeLa cells covered over the hyperdry human amniotic membrane (white arrow), (B) freezedried human amniotic membrane (white arrow head), and (D) collagen gel (black arrow). (C) There were no HeLa cells near the 2-octyl-cyanoacrylate (black arrow head). 
Table I Clinical characteristics and outcome of four cases treated with 2-octyl-cyanoacrylate

\begin{tabular}{|c|c|c|c|c|c|c|}
\hline Case & Age/gender & Eye & $\begin{array}{l}\text { Healing time } \\
\text { (day) }\end{array}$ & $\begin{array}{l}\text { Ocular conditions/ } \\
\text { perforation size } \\
(\mathrm{mm})\end{array}$ & Diagnosis & $\begin{array}{l}\text { The number } \\
\text { of applications }\end{array}$ \\
\hline 1 & $24 / M$ & $\mathrm{R}$ & 22 & $\begin{array}{l}\text { Corneal laceration } \\
(4 \mathrm{~mm})\end{array}$ & Trauma & 1 \\
\hline 2 & $82 / F$ & L & 19 & $\begin{array}{l}\text { Corneal perforation } \\
(1 \mathrm{~mm})\end{array}$ & $\begin{array}{l}\text { Syphilitic corneal } \\
\text { opacity }\end{array}$ & I \\
\hline 3 & $18 / F$ & $\mathrm{R}$ & 134 & $\begin{array}{l}\text { Bleb leaks } \\
(\mathrm{I} \mathrm{mm})\end{array}$ & $\begin{array}{l}\text { Developmental } \\
\text { glaucoma }\end{array}$ & 4 \\
\hline 4 & $45 / F$ & $\mathrm{R}$ & 17 & $\begin{array}{l}\text { Bleb leaks } \\
(1 \mathrm{~mm})\end{array}$ & $\begin{array}{l}\text { Developmental } \\
\text { glaucoma }\end{array}$ & 2 \\
\hline
\end{tabular}

( $1 \mathrm{~mm}$ in diameter) and aqueous leakage developed at the center of the opaque cornea (Figure 2A). A shallow anterior chamber was seen. The patient immediately underwent application of 2-octyl-cyanoacrylate to cover the perforated cornea. A bandage hydrogel contact lens was installed for support (Figure 2B). Nineteen days later, the hydrogel contact lens was carefully removed.
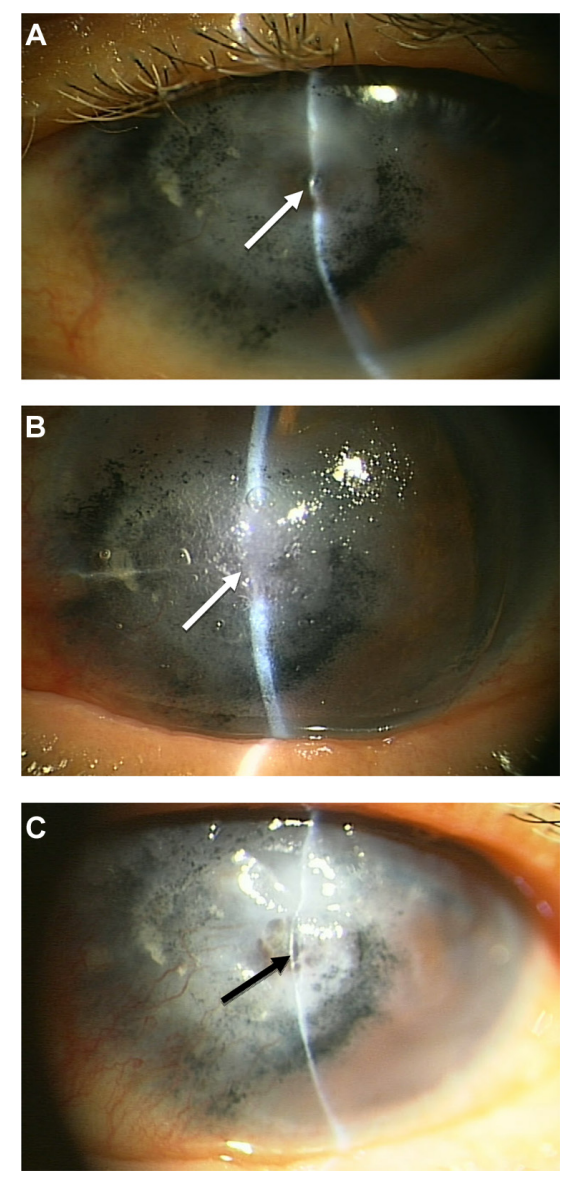

Figure 2 Patient 2, an 82-year-old woman. Preoperatively, corneal perforation with descemetocele (white arrow) was seen in the inferior paracentral area (A). The patient had received corneal tattooing approximately 40 years previously. Postoperatively, the perforation site was covered with glue and a hydrogel contact lens (white arrow) (B). Nineteen days later, the perforated site (black arrow) was closed (C).
No aqueous leak from the corneal lesion was seen (Figure 2C). The corneal surface of the repaired tissue was not stained by fluorescein dye. There has not been any recurrence of the perforation during follow-up of 12 months.

\section{Patient 4}

A 45-year-old woman was treated in our clinic for several years because of developmental glaucoma in both eyes. She had previously undergone bilateral multiple trabeculotomies at another hospital. She received phacoemulsification/ aspiration with intraocular lens implantation in the right eye in November 2002 and trabeculectomy enhanced by mitomycin C in March 2006. In May 2009, a small localized leak ( $1 \mathrm{~mm}$ in diameter) from an avascular bleb was noted in her right eye, and there were signs of bleb infection. Bacterial culture showed Staphylococcus aureus. Intraocular pressure in her right eye was $4 \mathrm{mmHg}$. She received levofloxacin $0.5 \%$ topically and cefazolin intravenously, and eventually underwent suturing of the leaking site. However, the leak did not disappear. She was treated with topical levofloxacin $0.5 \%$ conservatively. On July 13, 2010 and July 15, 2010, we applied 2-octyl-cyanoacrylate and a hydrogel contact lens as a bandage (Figure 3). There were no serious intraoperative or postoperative complications. Seventeen days later, the leak had disappeared. Intraocular pressure in her right eye was $12 \mathrm{mmHg}$. There was no recurrence of leaking bleb during the follow-up period of 18 months.

\section{Discussion}

We successfully treated patients with corneal perforation and bleb leak using 2-octyl-cyanoacrylate, a tissue adhesive. We recommend our procedure as an initial therapy for corneal perforation and avascular bleb leak. Taravella and Chang ${ }^{8}$ reported that 2-octyl-cyanoacrylate was effective for management of corneal perforation, and Kim et $\mathrm{al}^{6}$ 


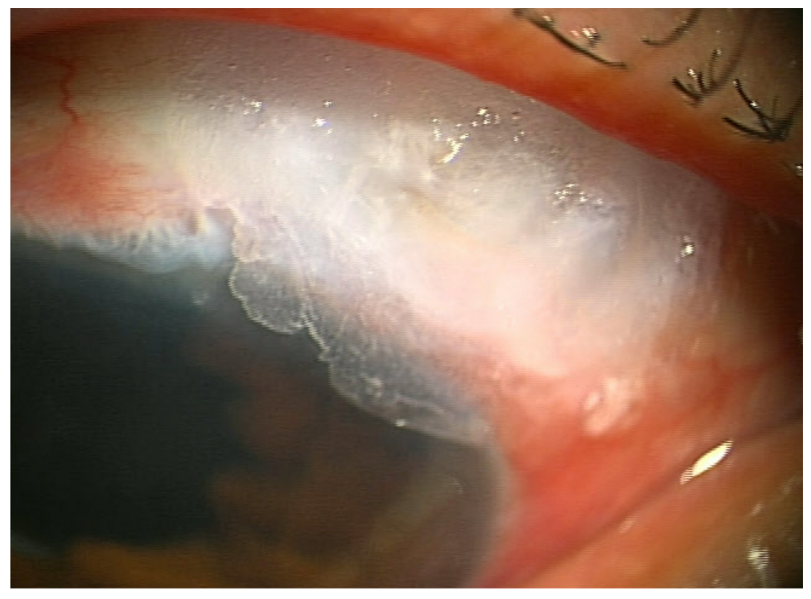

Figure 3 Patient 4, a 45-year-old woman. 2-Octyl-cyanoacrylate was secured on an avascular bleb leak.

Note: A hydrogel contact lens was installed to prevent ocular discomfort and to keep the adhesive from being dislodged from the bleb leak site.

reported that this adhesive had minimal toxic effects on ocular tissue.

2-Octyl-cyanoacrylate has not had any apparent adverse effects in any of our cases to date. In this study, we selected 2-octyl-cyanoacrylate as a sealant because we did not have clinical experience with any other tissue adhesives, such as fibrin glue. $\operatorname{Trott}^{10}$ reported that the cytotoxicity of 2-octyl cyanoacrylate depended on tissue vascularity and was increased in well vascularized soft tissue. In avascular tissue like the cornea or an avascular filtering bleb, 2-octyl cyanoacrylate may be suitable for repair. However, in our in vitro testing, 2-octyl-cyanoacrylate was cytotoxic in proliferating and migrating HeLa cells. In the present study, we could not evaluate the toxicity of 2-octyl-cyanoacrylate in human corneal cells because we did not have the necessary cell lines available. Further investigation is needed in this regard.

We used 2-octyl-cyanoacrylate adhesive and hydrogel bandage contact lenses simultaneously in our patients. Our previous experience was that, without using the hydrogel contact lens, the tissue adhesive applied fell off in the early postoperative period. Sharma et $\mathrm{al}^{4}$ reported that cyanoacrylate derivatives used simultaneously with a bandage contact lens were effective in repairing corneal perforations measuring up to $3 \mathrm{~mm}$ in diameter. They also reported that closure of corneal perforation was obtained within 6 weeks in seven of 22 eyes treated with cyanoacrylate derivatives, and that reapplication of the adhesive was needed in seven of 22 eyes during the follow-up period of 3 months. In our patients, corneal perforations up to $1 \mathrm{~mm}$ in diameter and linear lacerations up to $4 \mathrm{~mm}$ in diameter healed within 22 days, and no reapplication of adhesive was required. In patient 1, a $4 \mathrm{~mm}$ linear corneal laceration could be closed because of its sharp linear contour. Application of both 2-octyl-cyanoacrylate and a bandage contact lens may be sufficient for closure of corneal perforations up to $1 \mathrm{~mm}$ in diameter, but in patients with glaucoma and a leaking bleb, simultaneous use of the tissue adhesive and a bandage contact lens required multiple reapplications of the tissue adhesive in the present study. We used a $14 \mathrm{~mm}$ hydrogel contact lens as the bandage, and because the contact lens did not cover the bleb leak site, the glue applied dislodged spontaneously when the patient blinked before closure of the leak was achieved. The number of applications of tissue adhesive can be decreased if a larger contact lens can completely cover the bleb leak site. However, it is difficult to install a contact lens onto an irregular ocular surface or onto eyes with a protruding filtering bleb. In a previous study, ${ }^{1}$ we successfully treated cases of bleb leak with a HD-AM patch in combination with 2-octyl-cyanoacrylate and a hydrogel contact lens. Bleb leaks were successfully closed within 14 days, and no reapplications of the therapy were required. A superficially covered HD-AM patch might prevent the adhesive from dislodging from the leak site.

In conclusion, application of 2-octyl-cyanoacrylate is useful for repair of corneal perforation and bleb leak. This simple and easy technique may be an initial surgical option for the management of these ocular conditions, although reapplications of tissue adhesive may be required in patients with bleb leak.

\section{Disclosure}

The authors report no conflicts of interest in this work.

\section{References}

1. Kitagawa K, Yanagisawa S, Watanabe K, et al. A hyperdry amniotic membrane patch using a tissue adhesive for corneal perforations and bleb leaks. Am J Ophthalmol. 2009;148:383-389.

2. Kitagawa K, Okabe M, Yanagisawa S, Zhang XY, Nikaido T, Hayashi A. Use of a hyperdried cross-linked amniotic membrane as initial therapy for corneal perforations. Jpn J Ophthalmol. 2011;55:16-21.

3. Kitagawa K, Okabe M, Hayashi A, Nikaido T. Combined use of a novel dried cross-linked amniotic membrane and tissue adhesive to conjunctival defect following multiple trabeculectomy. Toyama Med J. 2009;20:1-3.

4. SharmaA, Kaur R, KumarS, etal. Fibrin glue versus N-butyl-2-cyanoacrylate in corneal perforations. Ophthalmology. 2003;110:291-298.

5. Meskin SW, Ritterband DC, Shapiro DE, et al. Liquid bandage (2-octyl cyanoacrylate) as a temporary wound barrier in clear corneal cataract surgery. Ophthalmology. 2005;112:2015-2021.

6. Kim YM, Gupta BK. 2-octyl cyanoacrylate adhesive for conjunctival wound closure in rabbits. Journal Pediatr Ophthalmol Strabismus. 2003;40:152-155.

7. Zalta AH, Wieder RH. Closure of leaking filtering blebs with cyanoacrylate tissue adhesive. Br J Ophthalmol. 1991;75:170-173.

8. Taravella MJ, Chang CD. 2-octyl cyanoacrylate medical adhesive in treatment of a corneal perforation. Cornea. 2001;20:220-221. 
9. Hurtado-Sarrió M, Duch-Samper A, Cisneros-Lanuza A, Diaz-LLopis M. Tachosil: a new alternative for the treatment of non-traumatic corneal perforations. Br J Ophthalmol. 2009;93:1410-1411.
10. Trott AT. Cyanoacrylate tissue adhesive. An advance in wound care. JAMA. 1977;277:1559-1560.

\section{Publish your work in this journal}

Clinical Ophthalmology is an international, peer-reviewed journal covering all subspecialties within ophthalmology. Key topics include: Optometry; Visual science; Pharmacology and drug therapy in eye diseases; Basic Sciences; Primary and Secondary eye care; Patien Safety and Quality of Care Improvements. This journal is indexed on Submit your manuscript here: http://www.dovepress.com/clinical-ophthalmology-journal

\section{Dovepress}

PubMed Central and CAS, and is the official journal of The Society of Clinical Ophthalmology (SCO). The manuscript management system is completely online and includes a very quick and fair peer-review system, which is all easy to use. Visit http://www.dovepress.com/ testimonials.php to read real quotes from published authors. 